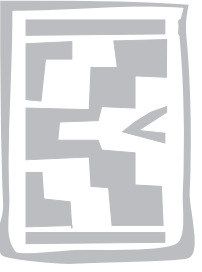

\title{
Prevalence of common gastrointestinal nematode parasites in scavenging pigs of different ages and sexes in eastern centre province, Burkina Faso
}

\author{
H.H. TAMBOURA ${ }^{1}$, H. BANGA-MBOKO2* D. MAES ${ }^{3}$, I. YOUSSAO ${ }^{4}$, A. TRAORE ${ }^{1}$, \\ B. BAYALA ${ }^{1}$ and M.A. DEMBELE ${ }^{5}$
}

\begin{abstract}
TAMBOURA, H.H., BANGA-MBOKO, H., MAES, D., YOUSSAO, I., TRAORE, A., BAYALA, B. \& DEMBELE, M.A. 2006. Prevalence of common gastrointestinal nematode parasites in scavenging pigs of different ages and sexes in Eastern Centre province, Burkina Faso. Onderstepoort Journal of Veterinary Research, 73:53-60
\end{abstract}

The range and infestation intensities of gastrointestinal parasitic nematode species depend on the type of swine production system. The present study focused mainly on nematodes of veterinary importance in scavenging pigs in Burkina Faso, and aimed at determining the prevalence of gastro-intestinal nematode parasites by means of faecal egg per gram (EPG) counts. Between November 2001 and October 2002, faecal samples from 383 pigs of different sexes and ages ( $<5$ months, 5-12 months and $>12$ months) were collected from the rectum and examined for gastrointestinal nematodes parasites using the Mc Master method. Of the 383 pigs examined, $91 \%$ were infected by one or more parasites. Ascaris suum (40\%; 100-1400 EPG) was the most prevalent parasite followed by Strongyloides ransomi (21\%; 100-4200 EPG), Oesophagostomum spp. (18\%; 100-1000 EPG), Hyostrongylus rubidus (11\%; 100-1800 EPG), Globocephalus spp. (10\%; 100-400 EPG) and Trichuris suis (1\%; 100-200 EPG). The prevalence was significantly higher in female pigs $(n=239)$ than in males. In addition, females excreted significantly $(P<0.05)$ more eggs in their faeces than males, except in the case of Globocephalus spp. The age of the animal had no effect on the prevalence of $A$. suum whereas there were significant differences in age categories concerning $S$. ransomi, $H$. rubidus, Oesophagostumum spp. and Globocephalus spp. Unexpectedly, the high prevalence of these common parasites was not accompanied by elevated EPG values, which suggests the existence of moderate infestations. The present work indicates that the common nematode infestations in pigs do not necessarily need a systematic herd anthelmintic treatment, as only a small number of worms is required to induce immunity.

A further study is needed to formulate appropriate and cost-effective strategies for the control of gastro-intestinal nematode parasites in pigs in Burkina Faso.

Keywords: Ascaris suum, Burkina Faso, Globocephalus spp., Hyostrongylus rubidus, Oesophagostomum spp., pigs, prevalence, Strongyloides ransomi, Trichuris suis

* Author to whom correspondence is to be directed. E-mail: henribanga@ hotmail.com

1 Environmental and Agricultural Research Institute (INERA), Department of Animal Productions 04, P.O. Box 8645, Ouagadougou, Burkina Faso

2 Marien Ngouabi University, Institute for Rural Development, Research Group on Local Animal Biodiversity, P.O. Box 69 Brazzaville Congo-Brazzaville

3 Ghent University, Faculty of Veterinary Medicine, Department of Reproduction, Obstetrics and Herd Health, Salisburylaan 133, 9820 Merelbeke, Belgium

4 University of Abomey-Calavi, Polytechnique School of AbomeyCalavi, Department of Animal Productions 01, P.O. Box 2009 Cotonou, Bénin

5 Regional Veterinary Laboratory of Tenkodogo P.O. Box 69, Tenkodogo, Burkina Faso

Accepted for publication 28 October 2005-Editor 


\section{INTRODUCTION}

Among the parasitic helminths, nematodes are considered as the most important worldwide. Most of them are unable to multiply inside the host and consequently they must leave it before the next generation can reach sexual maturity. Eggs and larvae are passed out of the body usually in large numbers. It follows, therefore, that each adult parasite must enter the host while still young, either as a contamination of pasture, food or water (Soulsby 1982).

Taking the above characteristics of the life cycle of nematode parasites into consideration, it is obvious that scavenging animals are more exposed to nematode infections. The occurrence of nematode parasites in scavenging pigs has been reported in several African countries such as Nigeria (Salifu, Manga \& Ponytail 1990), Zaire (Chartier, Mutesi \& Ndakala 1990), Zimbabwe (Borgsteede, Makinde \& Hill 1991), Ghana (Permin, Yelifari, Bloch, Steenhard, Hansen \& Nansen 1999), Cameroon (Tchoumboue, Tong \& Awah-Ndukum 2000) and Tanzania (Esrony, Kambarage, Mtambo, Muhairwa \& Kusiluka 1997; Ngowi, Kassuku, Maeda, Boa \& Willingham 2004).

Nansen \& Roepstorff (1999) reviewed the helminths in domesticated pigs. It appeared that Ascaris suum, Oesophagostomum spp. Trichuris suis, Hyostrongylus rubidus, Strongyloides ransomi, Metastrongylus spp. and Stephanurus dentatus were found to be the common helminths of veterinary importance in domesticated pigs.

Recently, in an abattoir survey on gastric infestations in scavenging pigs in Burkina Faso, BangaMboko, Tamboura, Maes, Traoré, Youssao, Sangild, El Amiri, Bayala, Remy \& Beckers (2003) reported a prevalence rate of $16.4 \%$ of $H$. rubidus infestation. The existence of $H$. rubidus as one of the common nematodes of veterinary importance prompted us to assess the complete spectrum of parasitic nematodes in scavenging pigs in Burkina Faso, as no such study has ever been carried out. The results of this study as well a suggested control strategy are reported here.

\section{MATERIAL AND METHODS}

\section{Study area}

Burkina Faso is a landlocked country located in the heart of west Africa, and borders Mali to the north and west, Niger to the east and Benin, Togo, Ghana and Ivory Coast to the south (Fig. 1). The climate is Sahelian in the north and Sudanian in the south of the country (Kagone 2001).
The study was conducted in the Tenkodogo town which is located in the Boulgou Province (one of 45 provinces of the country), the population is estimated to be about 515000 inhabitants in the Boulgou and 38000 in the Tenkodogo town over its six resident quarters. Tenkodogo is geographically located in the eastern centre part of Burkina Faso and is $200 \mathrm{~km}$ from Ouagadougou the capital of the country (Fig. 1).

Burkina Faso has a dry tropical climate. It is under seasonal alternation of moist air from the monsoon coming from oceanic high pressure and dry air from the Sahelian latitudes. The characteristics of the climates are two market seasons; a rainy season (hivernage) and a dry season. The dry season is at least as long as the rainy one, and an increasing aridity from south to north. The north of Burkina Faso has arid Sahelian climates while the South, namely the Sudanian ones, are less dry. The separation of the two climates corresponds to a line from Ouahigouya (see Fig 1). Tenkodogo is under the influence of both Sahelian and Sudanian climates, namely North Sudanian II which is characterized by a long dry season from November to May and a short rainy season from June to October. The mean annual rainfall is $800-900 \mathrm{~mm}$ and the monthly minimum and maximum temperatures are $22^{\circ} \mathrm{C}$ and $40^{\circ} \mathrm{C}$, respectively. The North Sudanian climates are characterized by savannahs which develop between $4-5$ months of rain. The growing season lasts $90-127$ days per year. Savannah groups are marked by agricultural activity, the population pressure as well as bush fires.

\section{Pig production}

Animal husbandry is the second most important national source of revenue, after cotton. Livestock products in Burkina Faso account for $19 \%$ of exports of which swine products (622493 heads of swine, mean of 1998) occupy the fourth range after those of cattle, sheep and goat, with an annual increase rate of $2 \%$ (Kagone 2001). Tenkodogo town is a suitable city to study the prevalence of nematode infections because $80 \%$ of its active inhabitants are crop or livestock farmers. Although the breeding of ruminants is more developed, pigs are traditionally raised for commercial purposes. The pigs, mainly males, are sold alive or are slaughtered in the Tenkodogo market or outside.

\section{Animals and sampling}

The present study started in November 2001 and ended in October 2002. In total, 60 pig keepers (ten 


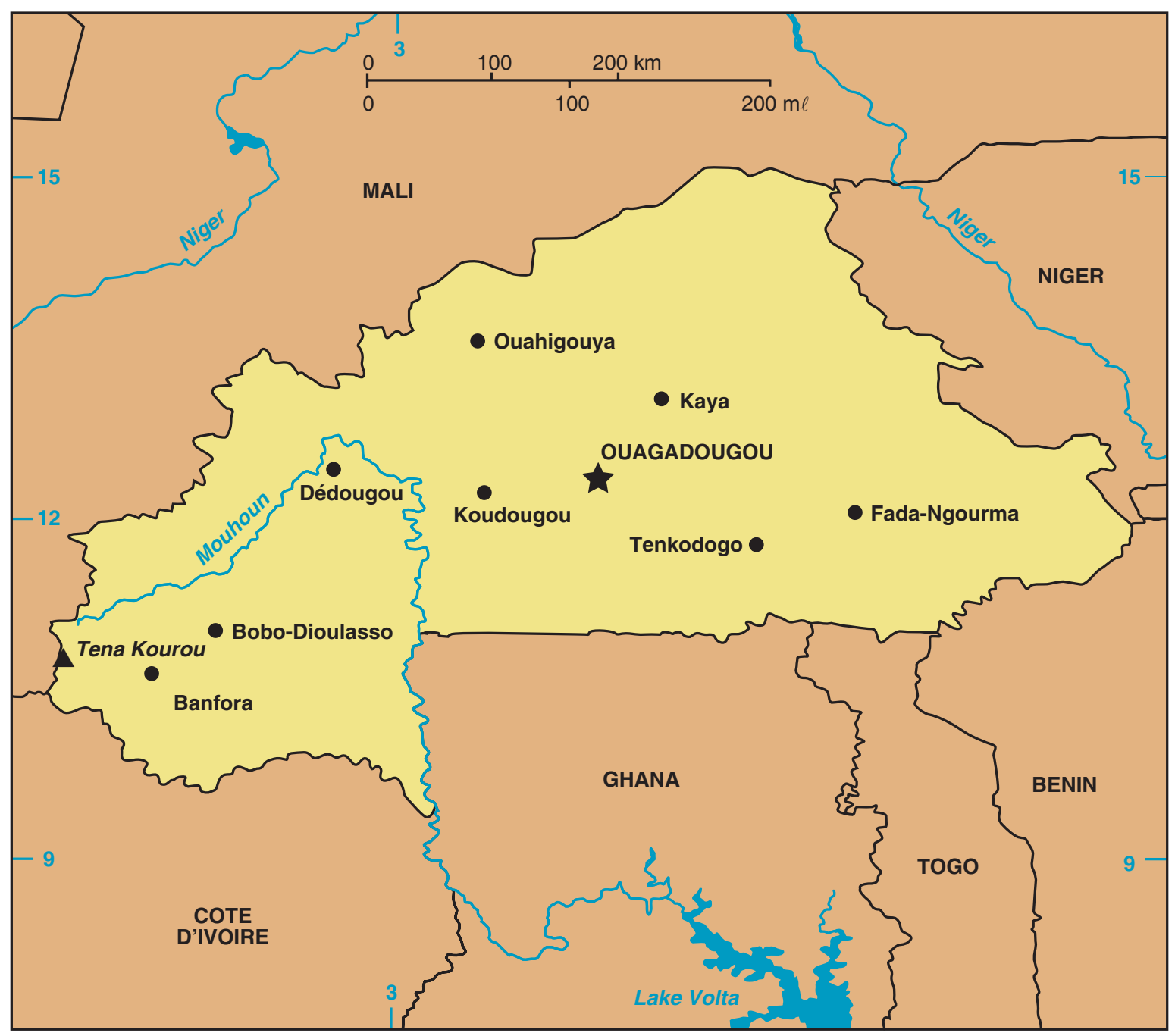

FIG. 1 Burkina Faso showing the location of the study area (Tenkodogo)

in each resident quarter) recorded by the regional department of Bolgou, were included in the survey. Three hundred and eighty three pigs (144 males and 239 females) were recorded and were of native breeds. They were not penned during the day but were housed overnight. They were categorised as young (0-4 months), young adults (5-12 months), and older adults (more than 12 months). Their distribution according to sex and age is given in Table 1.

\section{Sample collection}

Faecal samples were taken from the rectum and transported to the laboratory in a cool box where they were stored at $4{ }^{\circ} \mathrm{C}$ until processed.

\section{Faecal egg count}

Faecal egg counts were expressed as eggs per gram (EPG) using the Master Mc technique as sim- plified by Roepstorff \& Jorsal (1989) and Kaufmann (1996).

\section{Procedure}

For each sample, $3 \mathrm{~g}$ of faeces were deported into the first container and suspended in $42 \mathrm{~m} \ell$ of tap water. The mixture was then stirred thoroughly with a wooden spatula and passed through a $250 \mu \mathrm{m}$ aperture sieve, the filtrate was collected in a second container. The filtrate was then centrifuged at $100 \mathrm{~g}$ for $5 \mathrm{~min}$ and the liquid phase was discarded. The sediment was resuspended in a saturated salt solution $(400 \mathrm{~g} \mathrm{NaCl}$ and $1000 \mathrm{~m} \ell$ tap water) and stirred thoroughly again. The suspension was filtered again through a $250-\mu \mathrm{m}$ aperture sieve. Then, the filtrate was poured into a third container and the two chambers of a Master Mc chamber slides were filled with a Pasteur pipette. Microscopic examination was car- 
ried out at $10 \times 10$ magnification. The parasites were identified according to the keys listed by Thienpont, Rochette \& Vanparijs (1995) and Kaufmann (1996). Results were expressed as eggs per gram (EPG).

In order to distinguish eggs of Oesophagostomum spp. from those of $H$. rubidus a faecal sample was incubated and the L3 larvae were collected using the Baermann method as described by Thienpont et al. (1995) and Kaufmann (1996).

\section{Statistical analysis}

The prevalence was calculated as the ratio between the number of animals having the parasites and the number of surveyed pigs. The egg numbers were analysed according to the General Linear Model procedure (PROC GLM) of SAS (1989) using gender (male and female) and age (young, young adult and older adults) as factors of variation. The means were estimated and compared by the student t-test. Two means were statistically different when the $P$-value was $<0.05$.

\section{RESULTS}

\section{Parasitological examinations}

Of the 383 pigs examined, $92.7 \%(n=355)$ was found to be infected with one or more nematode species. The results are presented in Fig. 2. In addition to the 383 surveyed pigs, 443 observation occurrences of parasites were recorded as showed in Table 2. Six nematode species, of which five of veterinary importance, were identified: $A$. suum $(n=$ $179)$ followed by $S$. ransomi $(n=91)$ Oesophagostomum spp. $(n=78), H$. rubidus $(n=49)$ and $G$. urosulatus $(n=43)$, T. suis $(n=3)$ (Table 2). The prevalence and the EPG (mean and range) are given in Table 2. Forty percent of parasitized pigs were infected with $A$. suum, either as a single infestation or in association with other parasite species. In addition, only 14 pigs $(7.9 \%)$ had an EPG for $A$. suum ranging between 500 and 1400 . The occurrence and the association of $A$. suum with other parasites are shown in Table 3.

\section{Effect of sex on the prevalence and egg counts}

The prevalence was significantly higher in female pigs $(n=239)$ than in males $(n=144)$ with regard to Globocephalus spp. (24\% vs $19 \%$ ), Oesophagostomum spp. (53\% vs $25 \%$ ), A. suum (33\% vs $16 \%$ ), T. suis $(3 \%$ vs $0 \%)$ and to $S$. ransomi $(45 \%$ vs $46 \%)$. Overall, females excreted significantly $(P<$ $0.05)$ more eggs in their faeces than males, except for Globocephalus spp. The results are shown in Fig. 3.

\section{Effect of age on EPG}

As can be seen in Fig. 4, all pigs in the different age groups were infected with nematodes. Nevertheless, the adults young adults were more heavily infected with $S$. ransomi than were the young $(n=81)$ or the

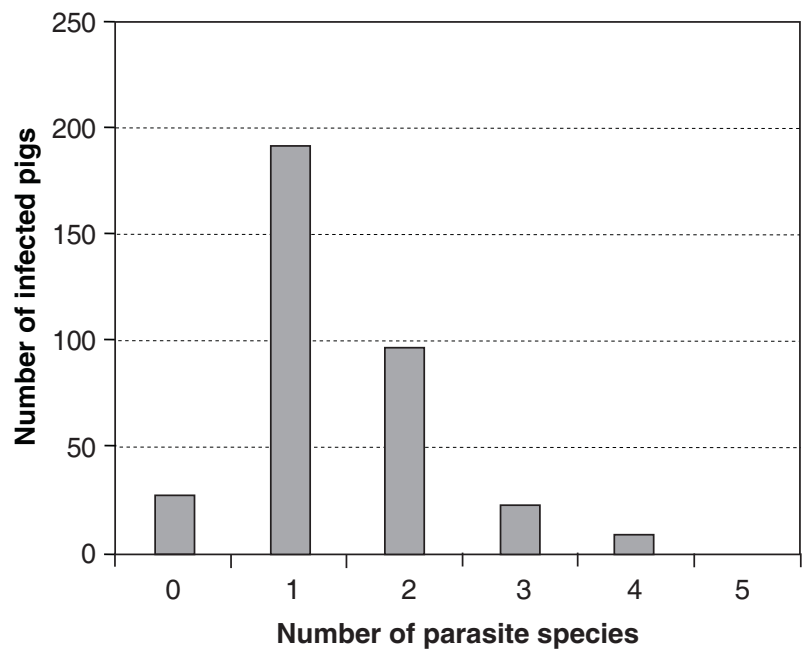

FIG. 2 Occurrence of common nematode parasites in scavenging pigs $(n=383)$ in the Eastern Centre Province, Burkina Faso. The occurrence picture of nematode parasites was drawn on the basis of 383 pigs of which 28 were free of parasites

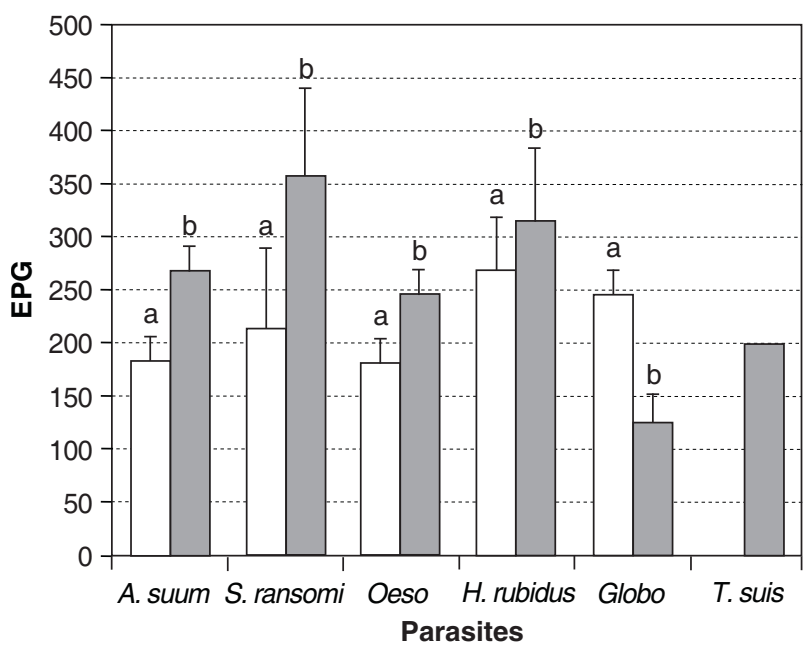

$$
\square \text { Males } \quad \square \text { Females }
$$

FIG. 3 EPG (Mean \pm S.E) according to the sex in scavenging pigs $(n=383)$ in the Eastern Centre Province, Burkina Faso. For each nematode parasite species, two means that are not followed by the same subscript letter are different $(P<0.05)$. No comparison was done as regards to $T$. suis since there were only three infected female pigs. Oeso = Oesophagostomum spp., Globo = Globocephalus spp. 


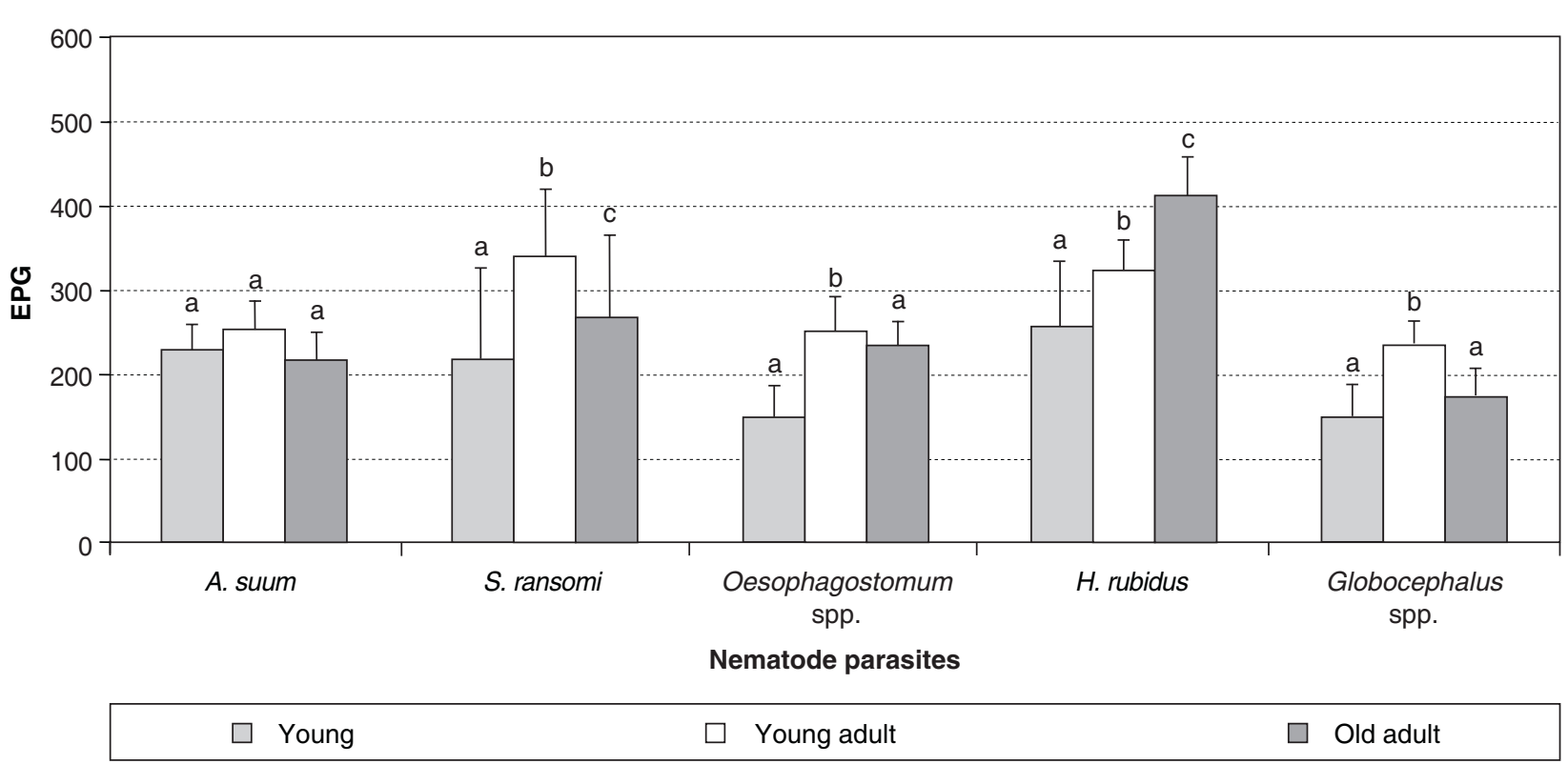

FIG. 4 EPG (Mean \pm S.E) according to age categories of scavenging pigs $(n=383)$ in the Eastern Centre Province, Burkina Faso. For each nematode parasite species, two means that are not followed by the same subscript letter are significantly different $(P<0.05)$. No comparison was done as regards to $T$. suis infected pigs; only females $(n=3)$ presented the same value

TABLE 1 Distribution of sampled pigs $(n=383)$ according to sex and age in the Eastern Centre Province, Burkina Faso

\begin{tabular}{|l|c|c|c|c|}
\hline \multirow{2}{*}{ Sex } & \multicolumn{2}{|l|}{ Age category } & \multirow{2}{*}{ Total } \\
\cline { 2 - 5 } & $\mathbf{2}$ months (young) & $\mathbf{5 - 1 2}$ months (young adult) & $\mathbf{> 1 2}$ months (older adult) & \\
\hline Male & 48 & 48 & 48 & 144 \\
Female & 80 & 80 & 79 & 239 \\
\hline Total & $\mathbf{1 2 8}$ & $\mathbf{1 2 8}$ & $\mathbf{1 2 7}$ & $\mathbf{3 8 3}$ \\
\hline
\end{tabular}

The age of the sampled pigs was determined on the basis of the pig keeper's declarations combined with teeth examination and measurement of body size

TABLE 2 Faecal examinations of common nematodes in scavenging pigs $(n=383)$ in the Eastern Centre Province, Burkina Faso

\begin{tabular}{|l|c|c|c|c|}
\hline Nematodes & Infected pigs & Prevalence (\%) & EPG (mean \pm SE) & Range EPG \\
\hline Ascaris suum & 179 & 40.40 & $231 \pm 201$ & $100-1400$ \\
Strongyloides ransomi & 91 & 20.55 & $290 \pm 555$ & $100-4200$ \\
Oesophagostomum spp. & 78 & 17.61 & $219 \pm 154$ & $100-800$ \\
Hyostrongylus rubidus & 49 & 11.06 & $326 \pm 335$ & $100-1800$ \\
Globocephalus spp. & 43 & 9.71 & $176 \pm 107$ & $100-400$ \\
Trichirus suis & 3 & 0.67 & $200 \pm 0$ & 200 \\
\hline Total & $\mathbf{4 4 3}$ & $\mathbf{1 0 0}$ & - & - \\
\hline
\end{tabular}

The prevalence rate was calculated on the basis of the number of pigs

Formula: Number of infected pigs x 100/383

older pigs $(n=138)$. In addition, old adult pigs were more infected with Globocephalus spp. and Oesophagostomum spp. than young and young adult pigs. The EPG values were similar in all groups with regard to $A$. suum, whereas there was a significant difference within age categories concerning $S$. ransomi, $H$. rubidus Oesophagostomum spp. and Globocephalus spp. Overall, the young and old adults excreted significantly more eggs than the younger pigs $(P<0.05)$. 
TABLE 3 Occurrence and association of Ascaris suum with other nematode parasites in scavenging pigs (383) in the Eastern Centre Province, Burkina Faso

\begin{tabular}{|l|r|r|}
\hline Parasites & Frequency & Percentage \\
\hline A alone & 97 & 54.00 \\
$\mathrm{~A}+\mathrm{H}$ & 12 & 7.00 \\
$\mathrm{~A}+\mathrm{G}$ & 11 & 6.00 \\
$\mathrm{~A}+\mathrm{O}$ & 35 & 20.00 \\
$\mathrm{~A}+\mathrm{S}$ & 4 & 2.00 \\
$\mathrm{~A}+\mathrm{G}+\mathrm{H}$ & 1 & 1.00 \\
$\mathrm{~A}+\mathrm{G} S$ & 5 & 3.00 \\
$\mathrm{~A}+\mathrm{O}+\mathrm{S}$ & 10 & 4.58 \\
$\mathrm{~A}+\mathrm{O}+\mathrm{H}$ & 1 & 0.56 \\
$\mathrm{~A}+\mathrm{G}+\mathrm{S}+\mathrm{T}$ & 1 & 0.56 \\
$\mathrm{~A}+\mathrm{O}+\mathrm{H}+\mathrm{S}$ & 1 & 0.56 \\
$\mathrm{~A}+\mathrm{O}+\mathrm{S}+\mathrm{T}$ & 1 & 0.56 \\
\hline
\end{tabular}

$\mathrm{A}=$ Ascaris suum

$\mathrm{H}=$ Hyostrongylus rubidus

$\mathrm{G}=$ Globocephalus spp.

$\mathrm{O}=$ Oesophagostomum spp.

$\mathrm{S}=$ Strongyloides ransomi

$\mathrm{T}=$ Trichirus suis

The prevalence rate was calculated on the basis of 179 pigs infected by $A$. suum, as below frequency x $100 / 179$

\section{DISCUSSION}

Of the seven nematode species listed as helminths of veterinary importance (Nansen \& Roepstorff 1999), five were found in scavenging pigs in the Tenkodogo town of Burkina Faso. Ninety two percent of the pigs were infested with one or more nematode species. Similar results have been reported in other African countries over the past 15 years (Chartier et al. 1990; Salifu et al. 1990; Borgsteede et al. 1991; Esrony et al. 1997; Permin et al. 1999; Nsoso, Mosala, Ndebele \& Ramabu 2000; Tchoumboue et al. 2000; Kagira, Kanyari, Munyua \& Waruiru 2002). Similar findings have been also reported in free range pigs in Belize (Gibbens, Gibbens \& Fielding 1989), Denmark (Roepstorff \& Jorsal 1989), Greece (Theodoropoulos, Deligeorgis, Fegeros, Papavasiliou, Helmis \& Rogdakis 2002), India (Kumar, Prasad, Singh \& Kumar 2002; Rajkhowa, Choudhury, Bujarbarruah, Mitali Dutta \& Dutta 2003). The high prevalences in African countries may be explained by the lack of an effective control system which would, however, to put it into practice, require more information about the epidemiological pattern, the availability of the new anthelmintics and the better education of the farmers.

The fact that $A$. suum was the most prevalent nematode agrees with other studies carried out in scavenging pigs (Yadav \& Tandon 1989; Salifu et al. 1990;
Kumar et al. 2002; Rajkhowa et al. 2003; Ngowi et al. 2004), in semi-intensive systems (Nsoso et al. $2000)$ or in organic swine herds (Carstensen, Vaarst \& Roepstorff 2002).

In 1989, Roepstorff \& Jorsal investigated the association of $A$. suum with other parasite species in Ghana. Their findings are similar to ours and confirm the occurrence of polyparasitism in scavenging pigs.

The prevalence of $H$. rubidus was lower than that found in our previous study (Banga-Mboko et al. 2003). This may be explained by the fact that in the former study, post mortem worm counts were performed. Furthermore, it is known that $H$. rubidus has a low fecundity and consequently produces a relatively small number of eggs (Roepstorff \& Nansen 1998).

Less than $20 \%$ of the pigs excreted eggs of S. ransomi. This prevalence rate did not differ much from that found by Gibbens et al. (1989), Esrony et al. (1997) and Permin et al. (1999) who described excretion rates of $2 \%, 9 \%$ and $1.5 \%$, respectively. By contrast, high levels of infection were observed by Salifu et al. (1990) and Rajkhowa et al. (2003) who found rates of $87 \%$ and $74 \%$, respectively.

Globocephalus spp. (8.5\%) infection was a fairly rare infestation as previously reported by Gibbens et al. (1989), Yadav \& Tandon (1989) and Permin et al. (1999) with $25 \%, 8 \%$ and $2.7 \%$, respectively.

Interestingly, $15.6 \%$ of the pigs excreted Oesophagostomum spp. eggs. This prevalence is lower than the rate of $45 \%$ of Gibbens et al. (1989), $27.6 \%$ of Yadav \& Tandon (1989), $40 \%$ of Esrony et al. (1997), $53 \%$ of Permin et al. (1999) and $27.6 \%$ of Kagira et al. (2002). This may be due to the lack of available vegetation and pasture during the large part of the year (Kraglund, Roepstorff \& Gronvold 2001).

The coprological examinations revealed that only $0.6 \%$ of the samples contained $T$. suis eggs. This low prevalence agrees well with the results of earlier studies in Belize (Gibbens et al. 1989), Denmark (Roepstorff \& Jorsal 1989) and Tanzania (Esrony et al. 1997) which indicate an extremely low infestation level. This supports the statement that despite the potential of long survival time for $T$. suis, its egg mortality is higher under field conditions (Nansen \& Roepstorff 1999).

Esrony et al. (1997), and later Nsoso et al. (2000) and Kumar et al. (2002), observed the effect of sex and age of pigs on the prevalence of helminth para- 
sites. Their findings agree with our data, indicating that nematode parasites have a wide occurrence spectrum.

Similar to the observations of Permin et al. (1999), the overall high prevalence of nematode infections was not associated with high EPG. For example, in A. suum infestation, the most common nematode, only $7.9 \%$ of pigs showed higher EPG. This is in contrast with the work of Nsoso et al. (2000) who found a mean EPG of 1500 vs 300 in the present study. It is possible that during our survey one part of the ascaris population might have just started to reach potency but may have already caused disease (Thienpont et al. 1995; Kaufmann 1996). Secondly, the mean EPG in Oesophagostomum spp. infestations found in this study was 219 units whereas in the heavy infestations in pigs, it may range between 3000 and 14000 EPG (Nansen \& Roepstorff 1999). This may be due to the short rainy season in the Tenkodogo area coupled with a long dry season which results in low environmental humidity. Such an environment would not satisfy the optimum requirements needed for the development of nematode eggs. Another explanation is that scavenging pigs being exposed for a long time to nematode infestations might develop an immunity that in sows could also be transferred passively to their offspring (Kelly \& Nayak 1965; Smith \& Herbert 1976; Murrell 1981; Eriksen, Lind, Nansen, Roepstorff \& Urban 1992). In addition, it is well known that one of the host's immunity reactions consists of the inhibition of the fecundity of female worms so that the number of eggs laid decreases in proportion to the increase of the host's resistance. In certain cases, the egg excretion can cease indefinitely (Thienpont et al. 1995).

The present work indicates that the common nematode infestations of pigs do not necessarily need a systematic herd anthelmintic treatment, but does suggest that some pigs should be dewormed at the end of the rainy season. The latter would prevent outbreaks of parasitic gastroenteritis during the long dry season and would reduce the carry-over of infestation into the next rainy season. Further investigations are required to formulate appropriate and cost-effective strategies to control gastro-intestinal nematode parasites of pigs in the Tenkodogo city.

\section{CONCLUSIONS}

Five of the seven common parasites of veterinary importance in pigs were found to infect pigs in Tenkodogo. Ascaris suum was the most common para- site and infested both sexes and different age categories. The prevalence rates of other parasites were influenced by sex and age. The occurrence of this large spectrum of parasites raises the question as to whether there are zoonotic parasites in scavenging pigs in Burkina Faso such as tapeworm (Cysticercus cellulosae) or Trichinella spiralis. In a community setting where pigs are reared and pig meat is consumed by a large part of the population, they could be involved in zoonotic helminthosis and a further investigation should study the possible impact of parasitic infestations of pigs on public health in Burkina Faso.

\section{ACKNOWLEDGEMENTS}

The authors thank Prof. Bertrand Losson, Department of Parasitology (Belgium) and Dr Mary-Louise Penrith (South Africa) for their constructive comments, Prof. Pascal Leroy, headmaster of the Institute for Tropical Veterinary Medicine (Belgium) for his financial help, Mogmenga Boukaré and Dénis François Bazie (Burkina Faso) for their technical assistance, and all the pig keepers whose pigs where surveyed for their excellent collaboration. One part of the study was funded by both INERA and the Regional Veterinary laboratory of Tenkodogo.

\section{REFERENCES}

BANGA-MBOKO, H., TAMBOURA, H., MAES, D., TRAORÉ, H., YOUSSAO, I., SANGILD, P.T., EL AMIRI, B., BAYALA, B., REMY B. \& BECKERS, J.F. 2003. Survey of gastric lesions and blood pepsinogen levels in pigs in Burkina Faso. Veterinary Research Communications, 27:595-602.

BORGSTEEDE, H.M., MAKINDE, M.O. \& Hill, F.W.G. 1991. Endoparasites of pigs in Zimbabwe. Zimbabwe Journal, 22: 129-131.

CARSTENSEN, L., VAARST, M. \& ROEPSTORFF, A. 2002. The helminth infections in Danish organic swine herds. Veterinary Parasitology, 106:253-264.

CHARTIER, C., MUTESI, U. \& NDAKALA, N.O. 1990. Les helminthes du porc domestique en Ituri, Haut Zaïre. Annales de la Société Belge de Médecine Tropicale, 70:213-225.

ERIKSEN, L., LIND, P., NANSEN, P., ROEPSTORFF, A. \& URBAN, J. 1992. Resistance to Ascaris suum in parasite naïve and naturally exposed growers, finishers and sows. Veterinary Parasitology, 41:137-149.

ESRONY, K., KAMBARAGE, D.M., MTAMBO, M.M.A., MUHAIRWA, A.P. \& KUSILUKA, L.J.M. 1997. Helminthosis in local and cross-bred pigs in the Morogoro region of Tanzania. Preventive Veterinary Medicine, 32:41-46.

GIBBENS, J.C., GIBBENS, N.P. \& FIELDING, W.J. 1989. An abattoir survey of the prevalence of gastro- intestinal helminths and Stephanurus dentatus in pigs in Belize. Tropical Animal and Health Production, 21:97-204 
KAGIRA, J.M., KANYARI, P.W.N., MUNYUA, W.K. \& WARUIRU, R.M. 2002. The prevalence of gastrointestinal parasites in commercial pig farms in Thika district, Kenya. Bulletin of Animal Health and Production in Africa, 50:1-7.

KAGONE, H. 2001. Grass land and pasture crops in Burkina Faso. FAO: http://www.fao.org/WAICENT/FAO/AGRICULT/ AGP/doc/pasture/pasture/htm, consulted on June $10^{\text {th }} 2004$.

KAUFMANN, J. 1996. Parasitic infections of domestic animals, a diagnostic manual. Basel: Birkhauser Verlag.

KELLY, G.W. \& NAYALK, D.P. 1965. Passive immunity to Asaris suum transferred in colostrums from sows to their offspring. American Journal of Veterinary Research, 26:948-950.

KRAGLUND, H.O., ROEPSTORFF, A. \& GRONVOLD, J. 2001. The impact of season and vegetation on the survival and development of Oesophagostomum dentatum larvae in pasture plots. Parasitology, 123:415-423.

KUMAR, S., PRASAD, K.D., SINGH, S.K. \& KUMAR, S. 2002. Prevalence of common gastrointestinal parasites in pigs at and around Ranchi, Jharhand. Indian Journal of Animal Sciences, 72:35-37.

MURRELL, K.D. 1981. Induction of protective immunity to Strongyloides ransomi in pigs. American Journal of Veterinary Research, 42:1915-1919.

NANSEN, P. \& ROEPSTORFF, A. 1999. Parasitic helminths of the pig: factors influencing transmission and infection levels; International Journal for Parasitology, 29:877-891.

NGOWI, H.A., KASSUKU, A.A., MAEDA, G.E., BOA, M.E. \& WILLINGHAM, A.L. 2004. A slaughter slab survey for extra-intestinal porcine helminth infections in northern Tanzania. Tropical Animal and Health Production, 36:335-340.

NSOSO, S.J., MOSALA, K.P., NDEBELE, R.T. \& RAMABU, S.S. 2000. The prevalence of internal and external parasites in pigs of different age and sexes in southeast district, Botswana. Onderstepoort Journal of Veterinary Research, 67: 217-220.

PERMIN, A., YELIFARI, L., BLOCH, P., STEENHARD, N. HANSEN, N.P. \& NANSEN, P. 1999. Parasites in cross- bred pigs in the upper east region of Ghana. Veterinary Parasitology, 87:63-71.

RAJKHOWA, S., CHOUDHURY, H., BUJARBARRUAH, K.M., MITALI DUTTA \& DUTTA, M. 2003. The prevalence of gastrointestinal nematodes in indigenous pigs of Nagaland. Indian Journal of Veterinary Medicine, 23:1-3.

ROEPSTORFF, A. \& JORSAL, S.E. 1989. Prevalence of helminth infections in swine in Denmark. Veterinary Parasitology, 133: 231-239.

SALIFU, D.A., MANGA, T.B. \& PONYTAIL, I.O. 1990. A survey of gastro intestinal parasites in pigs of the plateau and rivers states of Nigeria. Revue d'Elevage et de Médecine Vétérinaire des Pays Tropicaux, 43:193-196.

SAS Institute. SAS User's guide. 1989. Cary N.C.: StatisticSAS Institute Inc.

SMITH, H.V. \& HERBERT, I.V. 1976. The passive transfer of humoral immunity from sows infected with Hyostrongylus rubidus (Hassal and Stiles, 1892), the red stomach worm, to their offsprings and its significance in the conferring of protective immunity. Immunology, 30:213-219.

SOULSBY, E.J.L. 1982. Helminths, arthropods and protozoa of domesticated animals. London: Baillière Tindall.

TCHOUMBOUE, J., TONG, J.C. \& AWAH-NDUKUM, J. 2000. Prevalence of gastrointestinal parasites of pigs in the western highlands of Cameroon. Bulletin of Animal Health and Production in Africa, 483:183-186.

THEODOROPOULOS, G., DELIGEORGIS, S., FEGEROS, K., PAPAVASILIOU, D., HELMIS, G. \& ROGDAKIS, E. 2002. Parasites in indigenous Greek pigs kept in an extensive organic production system. Agricoltura Mediterranea, 132:253258.

THIENPONT, D., ROCHETTE, F. \& VANPARIJS, O.F.J. 1995. Diagnostic des verminoses par examen coprologique, $2^{\text {nd }}$ ed. Beerse, Belgium: Janssen Research Foundation.

YADAV, A.K. \& TANDON, V. 1989. Nematode parasite infections of domestic pigs in a sub-tropical and high-rainfall area of India. Veterinary Parasitology, 31:133-139. 